\title{
Example of analysis of climatic data series with respect to the testing of reinforcement concrete corrosion in a climate chamber
}

\author{
Petr Lehner ${ }^{1,}$, Petr Konečný ${ }^{1}$ and Ryszard Walentyński ${ }^{2}$ \\ ${ }^{1}$ VSB - Technical University of Ostrava, Faculty of Civil Engineering, Department of Structural \\ Mechanics, Ludvíka Podéště 1875/17, 70833 Ostrava-Poruba, Czech Republic \\ ${ }^{2}$ Silesian University of Technology, Faculty of Civil Engineering, Department of Mechanics and \\ Bridges, ul. Akademicka 5, pok. 124, 44-100 Gliwice, Poland
}

\begin{abstract}
The paper presents a possible statistical evaluation of the climate data, namely temperature and relative humidity, with respect to the rapid evaluation of the risk of reinforced concrete corrosion in the laboratory conditions. Data on temperature and humidity from Leoš Janáček Ostrava Airport over the last ten years are analysed. The processed data will be used as the set up for the climate chamber where the concrete samples with steel rods will be placed.
\end{abstract}

\section{Introduction}

Reinforced concrete bridges in Central Europe, are typically exposed to the combined effect of carbonation, chlorides ingress, and mechanical load. First two factors are typically influenced by the value of loading as well as environmental parameters such as temperature, moisture as well as wind speed [1]. It is well known that these reinforced concrete structures are susceptible to corrosion that can have an influence on load-carrying capacity decay and consequently threaten safety. One possible way to evaluate this durability related issue is the connection with corrosion initiation modelling [2] and internal forces computation for the analysis of minimal required steel reinforcement cross-sectional area via the bending limit equilibrium equation concerning the effect of corrosion initiation and progress. Since the concrete cover role is, in most cases, to protect steel reinforcement, a correct analytical or numerical description of its resistance is also important [3-6]. Similarly, there is a need to expand the possibilities of a laboratory as well as real-time measuring. In-situ measurements of corrosion rate of reinforcement in concrete structures involve more advanced electrochemical methods, from Linear Polarization Resistance LPR [7], to advance measurements by means of Electrochemical Impedance Spectroscopy EIS $[8,9]$. For these tests, it is very important to have climate data related to the expected location of the structure.

The objective of this paper was to analyse real measured data from the weather station Leoš Janáček Ostrava Airport. From the available climate data, the temperature and the

* Corresponding author: petr.lehner@vsb.cz 
humidity over the last ten years were analysed and these results will be utilized later for polarization measurements conducted by Linear Polarization Resistance and Electrochemical Impedance Spectroscopy techniques [10]. The measurements will be carried out in a continuous mode on concrete specimens with passive reinforcement and advanced corrosion. The tests will be performed in a climatic and corrosion chamber under predefined temperature and humidity conditions that are location-dependent as mentioned above.

\section{Temperature and humidity data set}

The combinations of relative humidity $(\mathrm{RH})$ and temperature $(\mathrm{T})$ are often described as a temperature-humidity complex (T-HC). This complex is commonly used by scientists and industry to design experiments. The atmospheric parameters $\mathrm{T}$ and $\mathrm{RH}$ are usually reported in average monthly and yearly values, but in many cases, the interpretation of research results may be misleading or even completely incorrect [11]. In the testing in the climatic chamber, the standards shall be followed, or a combination of the highest temperature and highest humidity in the first part of the cycle shall be chosen and the lowest temperature and lowest humidity in the other part of the cycle. For this reason, it is advisable to determine how often these combinations occur for a selected location of the globe.

\subsection{Processing and retrieving the input data}

The first step was to obtain accurate data from temperature and relative humidity measurements between 2010 and 2019 from Ostrava (Leoš Janáček Ostrava Airport) (see Fig. 1). An algorithm cooperating with the online search engine Wolfram Alfa [12] was created for this purpose. Looking at the data, it is clear that several basic parameters can be evaluated using statistical operations. For these and other operations, a complex algorithm was created in Matlab software [13]. Its properties are described below.
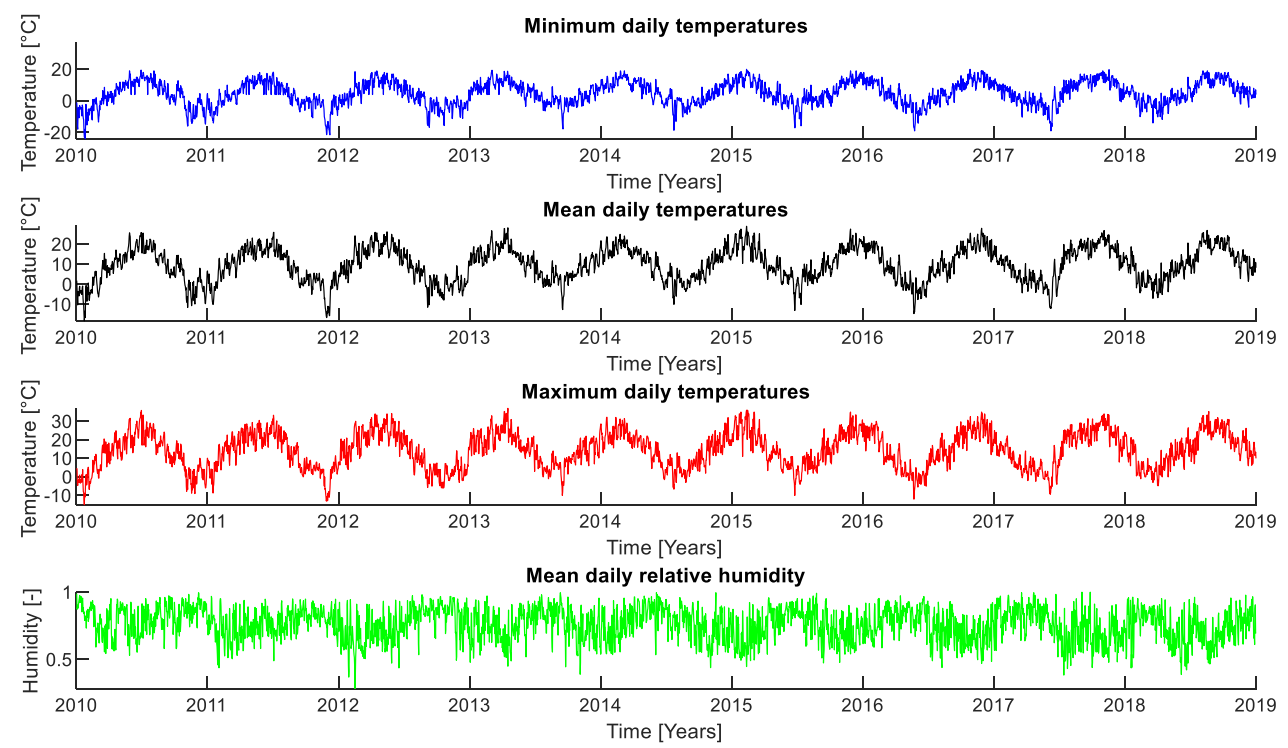

Fig. 1. Minimum, maximum and mean temperatures and mean humidity values for the Ostrava area for every day between 2010 and 2019. 


\subsection{Analysis by years}

The primary data of daily temperature (minimums, maximums and mean) and humidity had to be transformed into the correct format for further statistical evaluation. The algorithm loads the available data into a matrix file that contains the year, month, day, and value to be evaluated. This allows the desired results to be evaluated and plotted in a few automatic steps. Firstly, a statistical evaluation of the basic variables was undertaken. The selection of the annual averages of all four variables (see Table 1.) and then extreme values for all data (see Table 2.) was important for the next evaluation.

Table 1. Annual averages of the humidity, and minimum, maximum and mean temperatures.

\begin{tabular}{|c|c|c|c|c|c|c|c|c|c|c|c|}
\hline Year & $\mathbf{2 0 1 0}$ & $\mathbf{2 0 1 1}$ & $\mathbf{2 0 1 2}$ & $\mathbf{2 0 1 3}$ & $\mathbf{2 0 1 4}$ & $\mathbf{2 0 1 5}$ & $\mathbf{2 0 1 6}$ & $\mathbf{2 0 1 7}$ & $\mathbf{2 0 1 8}$ & $\mathbf{2 0 1 9}$ & Averages \\
\hline $\begin{array}{c}\text { Minimum } \\
\text { temperature } \\
{\left[{ }^{\circ} \mathbf{C}\right]}\end{array}$ & 3.34 & 3.79 & 3.83 & 4.31 & 5.49 & 5.05 & 5.06 & 4.85 & 5.53 & 5.52 & 4.68 \\
\hline $\begin{array}{c}\text { Mean } \\
\text { temperature } \\
{\left[{ }^{\circ} \mathbf{C}\right]}\end{array}$ & 7.93 & 9.21 & 9.26 & 8.90 & 10.33 & 10.26 & 9.77 & 9.54 & 10.48 & 10.23 & 9.59 \\
\hline $\begin{array}{c}\text { Maximum } \\
\text { temperature } \\
{\left[{ }^{\circ} \mathbf{C}\right]}\end{array}$ & 12.53 & 14.15 & 14.12 & 13.05 & 14.93 & 14.75 & 14.13 & 13.85 & 15.13 & 14.66 & 14.13 \\
\hline \begin{tabular}{c} 
Humidity [-] \\
\hline
\end{tabular} & 0.79 & 0.77 & 0.75 & 0.77 & 0.78 & 0.73 & 0.75 & 0.75 & 0.72 & 0.63 & 0.75 \\
\hline
\end{tabular}

Table 2. Extreme value for all parameters over the entire research period.

\begin{tabular}{|c|c|c|c|c|}
\hline & $\begin{array}{c}\text { Minimum } \\
\text { temperature }\end{array}$ & $\begin{array}{c}\text { Mean } \\
\text { temperature }\end{array}$ & $\begin{array}{c}\text { Maximum } \\
\text { temperature }\end{array}$ & Humidity \\
\hline $\min$ & $-24^{\circ} \mathrm{C}$ & $-18.22^{\circ} \mathrm{C}$ & $-15^{\circ} \mathrm{C}$ & 0.284 \\
\hline $\max$ & $20^{\circ} \mathrm{C}$ & $28.94^{\circ} \mathrm{C}$ & $37^{\circ} \mathrm{C}$ & 1.000 \\
\hline
\end{tabular}

Comparing values in Tables 1 and 2, it is clear that annual average values cannot capture the extremes that may occur. In the Ostrava area, the lowest daily minimum temperature was $-24^{\circ} \mathrm{C}$ and the highest maximum temperature was $37^{\circ} \mathrm{C}$ in the past decade. Thus, annual average values cannot provide sufficiently accurate information on the rate of temperature and humidity change and about their combinations. It is these changes that can have a significant effect and are important in terms of corrosion of reinforced concrete structures.

Taking the values from Table 1 as input data for climate chambers, we could choose a temperature cycle from $4.68^{\circ} \mathrm{C}$ to $14.13^{\circ} \mathrm{C}$. There would be a problem with determining adequate humidity, which corresponds to low and high temperature since the average value cannot be used. Similarly, the values in Table 2, i.e. the cycle from $-24^{\circ} \mathrm{C}$ to $37^{\circ} \mathrm{C}$, is not adequate because it shows a wide range. In addition, corrosion does not occur at temperatures below $3^{\circ} \mathrm{C}$ to $5^{\circ} \mathrm{C}$ (depending on humidity). Therefore, the data needs to be evaluated more in-depth. 


\subsection{Analysis by months}

The next step may be to evaluate monthly averages that are more consistent with changes in our temperate climate zone (see Fig. 2). It should be noted here, that the algorithm is designed to classify information regardless of the length of studied time and location. Such an evaluation method is desirable with respect to laboratory testing related activities to structures in different climate zones with different temperature variations. However, monthly average values are still dependent on the number of years that are examined. This may have affected the results that may be misinterpreted.
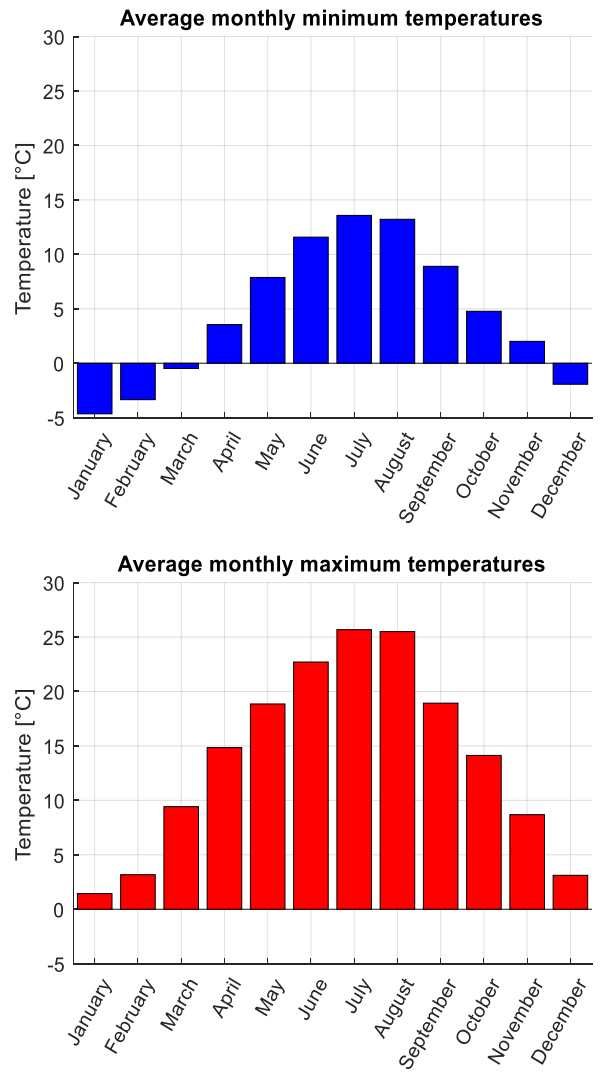
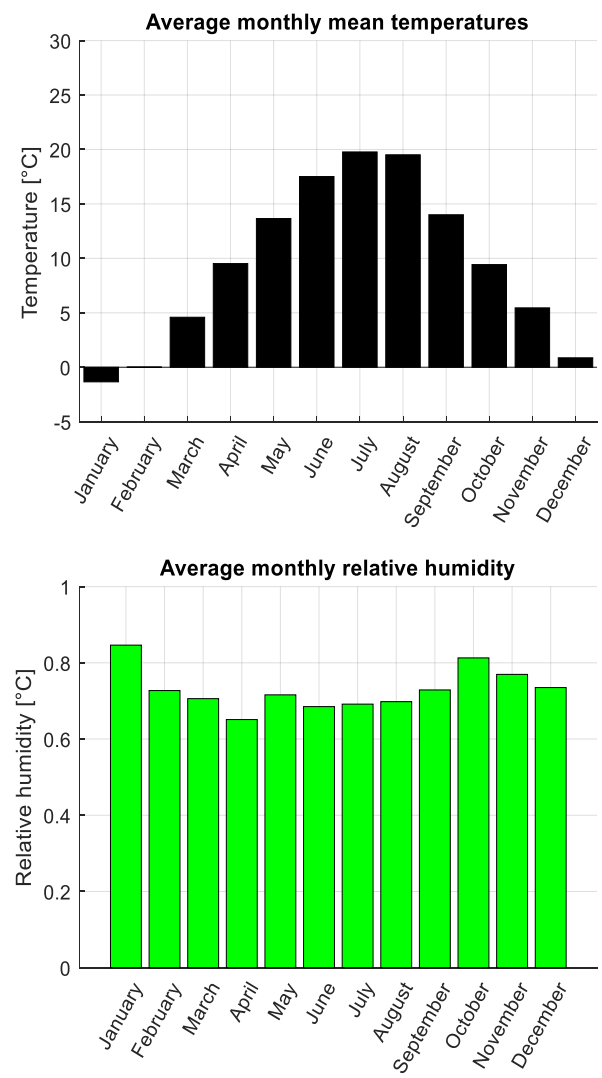

Fig. 2. Minimum, mean and maximum temperatures and mean humidity values for the Ostrava area for every day between 2010 and 2019.

An example of simple analysis can be as follow: The highest average maximum temperature is in July $\left(25.68^{\circ} \mathrm{C}\right)$ and the average humidity this month is 0.7 . The counterpart of the climate chamber cycle data set should be set around $5^{\circ} \mathrm{C}$ [14], which is observed in October and has an average monthly humidity of 0.81 . With such a simple analysis, we find that the data are not suitable as inputs for climate chambers because we have to find the most common combination of high temperature with high humidity and low temperature with low humidity. In terms of monthly averages, however, the correlation between temperature and humidity is negative. That is why it is necessary to use the next step - the analysing of each day separately and finding extreme combinations with subsequent quantification. 


\section{Daily analysis and deeper sorting}

Before searching for extreme combinations and their amount, it is necessary to sort daily values. The reason is to determine the appropriate limits for finding a certain number of extreme combinations. It is sufficient to express percentage values for minimum and maximum temperatures and for relative humidity (see Fig. 3).
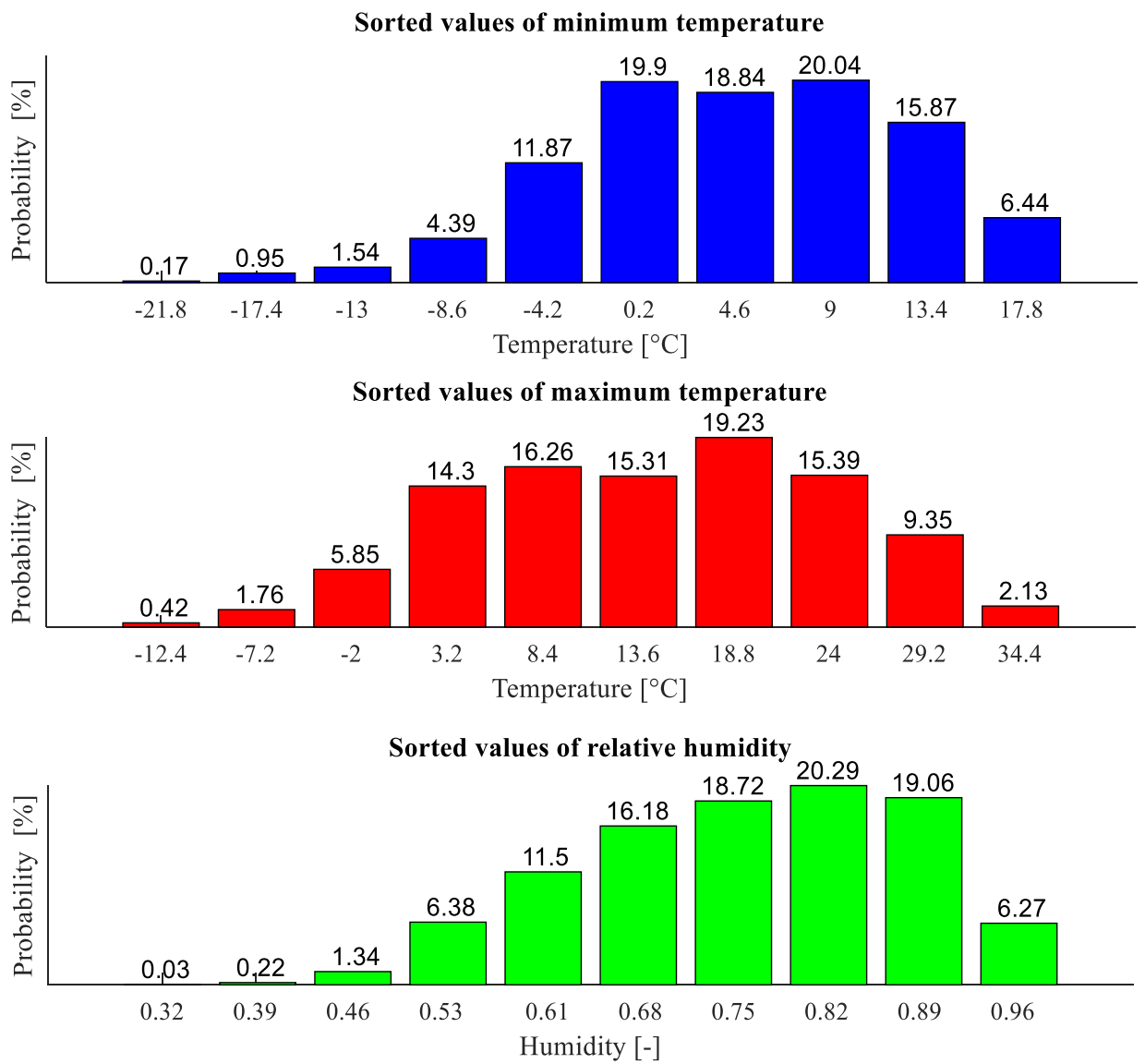

Fig. 3. A histograms of minimum and maximum temperatures, and of humidity expressed as probability [\%].

This simple sorting is not yet the sufficient result because it does not reflect how often low temperatures and low humidity are combined, as well as high temperature and high humidity. Since temperatures have a negative correlation to humidity, more complex sorting is required. As mentioned above, temperatures of about $5^{\circ} \mathrm{C}$ are selected for the bottom side of the load cycle in the climate chamber [14].

Therefore, a searching algorithm was prepared, which finds a range of minimum temperatures in the range of $2^{\circ} \mathrm{C}$ to $8^{\circ} \mathrm{C}$ and humidity on the same day in the range of 0.2 to 0.7 . Searching was done for every day in the time range (see Table 3 - Bottom range). 
For the upper side of the load cycle in the climate chamber, a range of maximum temperatures in the range of $20^{\circ} \mathrm{C}$ to $37^{\circ} \mathrm{C}$ and humidity on the same day in the range of 0.7 to 1.0 was chosen. Searching was done for every day in the time range too (see Table 3 - Upper range).

Another possibility was to find the days when the difference between the smallest and the highest temperature was more than $15^{\circ} \mathrm{C}$ and at the same time, the humidity exceeded 0.7 . At the same time, there was a condition that the lowest maximum temperature must be higher than $3^{\circ} \mathrm{C}$ (see Table 3 - Difference range).

Table 3. Results of the number of values according to selected ranges found in the total of 3573 days.

\begin{tabular}{|c|c|c|c|}
\hline Selected ranges & Quantification & $\begin{array}{c}\text { Probability of } \\
\text { occurrence }\end{array}$ & $\begin{array}{c}\text { Climate chamber } \\
\text { probability }\end{array}$ \\
\hline $\begin{array}{c}\text { Bottom range } \\
\text { temperature } 2{ }^{\circ} \mathrm{C} \div 8^{\circ} \mathrm{C}, \\
\text { humidity } 0.2 \div 0.7\end{array}$ & 330 days & $9.24 \%$ & $39.78 \%$ \\
\hline $\begin{array}{c}\text { Upper range } \\
\text { temperature } 20^{\circ} \mathrm{C} \div 37^{\circ} \mathrm{C}, \\
\text { humidity } 0.7 \div 1.0\end{array}$ & 500 days & $13.99 \%$ & $60.22 \%$ \\
\hline $\begin{array}{c}\text { Differences range } \\
\text { temperature difference } 15^{\circ} \mathrm{C}<, \\
\text { temperature } 3{ }^{\circ} \mathrm{C}<, \\
\text { humidity } 0.7<\end{array}$ & 74 days & $2.07 \%$ & - \\
\hline
\end{tabular}

The probability of selected temperature and humidity interactions suitable for the climate chamber with respect to the selection of effective cycling related to speed up the steel corrosion process is given. Actual probabilities are weighted and given the distribution share for the simulation in the chamber. Combination of the first two sets of results is appropriate as the setting distribution for climate chambers for the Ostrava region.

However, the third result is not suitable, because it is not often the case that the temperature change by $15^{\circ} \mathrm{C}$ on the same day. This fact may be significant elsewhere.

This indicates that the standardized climate chamber test procedure does not fit the climate conditions in this area. From this point of view, it was suitable to study the sorting of input data, which will serve as a suitable basis setting for climate chambers testing reinforced concrete structures.

This is related to, that the ranges described in Table 3 above that can be changed at any time and a new sorting can be performed. This complexity and generality of the procedure are advantageous in view of future testing of reinforced concrete samples in climatic chambers. Since range changes can significantly change the ratios between results, further research is desirable. Similarly, the reduced range is likely to affect results.

\section{Conclusions}

The possible statistical evaluation of the climate data is presented. Temperature and relative humidity were chosen because they relate to concrete corrosion in reinforcement structures. Available information from weather station Leoš Janáček Ostrava Airport was taken from online databases via the Wolfram Alfa algorithm. Statistical evaluation and sorting process were prepared in Matlab algorithm. Both computing systems are prepared in general and can be used for a large number of cases. In this example, the data for the climate chamber was analysed. 
During the preparation of the data set, it was found out that it is not appropriate to use either annual or monthly averages, as they do not correspond to actual changes in temperature and humidity. Furthermore, they do not depict the reality of the combinations of these two parameters.

Although it is not a standard case in structural mechanics, its solution and proper handling of procedures can be of great help in testing structures exposed to adverse weather conditions. For further research, it will be interesting to prepare a prediction of temperature and humidity development based on the trend of recent years. It should also be noted that the whole algorithm can be applied to other types of load, i.e. wind, snow etc. Another approach will also be to introduce online sensors directly into reinforced concrete structures to account for the actual temperature and humidity load. Even the data obtained in this way will be correctly analysed and sorted.

This article has been prepared as a part of the research project GACR 18-07949S "Probabilistic Modeling of the Durability of Reinforced Concrete Structures Considering Synergic Effect of Carbonation, Chlorides and Mechanical Action" funded by the Czech Science Foundation. Financial support is highly acknowledged.

\section{References}

[1] D. Vořechovská, J. Podroužek, M. Chromá, P. Rovnaníková, B. Teplý, Comput. Civ. Infrastruct. Eng. 24, 446-458 (2009)

[2] P. Konečný, P. Lehner, J. Brožovský, M. Krejsa, Civil-Comp Proc. 108 (2015)

[3] D.P. Bentz, E.J. Garboczi, Y. Lu, N. Martys, A.R. Sakulich, W.J. Weiss, Cem. Concr. Compos. 38, 65-74 (2013)

[4] P. Konečný, P. Lehner, D. Pustka, Period. Polytech. Civ. Eng. 63 (2019)

[5] T.D. Le, P. Lehner, P. Konečný, Materials (Basel, 2019)

[6] Z. Szweda, A. Zybura, Procedia Eng. 57, 1121-1130 (2013)

[7] C. Andrade, C. Alonso, Constr. Build. Mater, (1996)

[8] T. Jaśniok, A. Zybura, Arch. Civ. Eng. (2007)

[9] M. Jaśniok, Investigation and modelling of the impact of reinforcement diameter in concrete on shapes of impedance spectra, in: Procedia Eng., (2013): pp. 456-465

[10] M. Jasniok, Procedia Eng. 108, 332-339 (2015)

[11] L. Veleva, G. Pérez, M. Acosta, Atmos. Environ. (1997)

[12] Wolfram|Alpha Knowledgebase from http://www.wolframalpha.com/ with query, (2019)

[13] Mathworks, n.d. www.mathworks.com/products/matlab/

[14] M. Jaśniok, T. Jaśniok, Evaluation of Maximum and Minimum Corrosion Rate of Steel Rebars in Concrete Structures, Based on Laboratory Measurements on Drilled Cores, in: Procedia Eng., 486-493 (2017) 